\title{
Relationship between low hemoglobin levels and mortality in patients with septic shock
}

\author{
Sung Min Jung, Youn-Jung Kim, Seung Mok Ryoo, Won Young Kim \\ Department of Emergency Medicine, Asan Medical Center, University of Ulsan College of Medicine, Seoul, Korea
}

Background: Hemoglobin levels are a critical parameter for oxygen delivery in patients with shock. On comparing target hemoglobin levels upon transfusion initiation, the correlation between the severity of decrease in hemoglobin levels and patient outcomes remains unclear. We evaluated the association between initial hemoglobin levels and mortality in patients with septic shock treated with protocol-driven resuscitation bundle therapy at an emergency department.

Methods: Data of adult patients diagnosed with septic shock between June 2012 and December 2016 were extracted from a prospectively compiled septic shock registry at a single academic medical center. Patients were classified into four groups according to initial hemoglobin levels: $\geq 9.0 \mathrm{~g} / \mathrm{dl}, 8.0-8.9 \mathrm{~g} / \mathrm{dl}, 7.0-7.9 \mathrm{~g} / \mathrm{dl}$, and $<7.0 \mathrm{~g} / \mathrm{dl}$. The primary endpoint was 90-day mortality.

Results: In total, 2,265 patients (male, 58.3\%; median age, 70.0 years [interquartile range, 60 to 78 years]) with septic shock were included. For the four groups, 90-day mortality rates were as follows: $29.1 \%, 43.0 \%, 46.5 \%$, and $46.9 \%$ for $\geq 9.0 \mathrm{~g} / \mathrm{dl}(\mathrm{n}=1,808), 8.0-8.9 \mathrm{~g} / \mathrm{dl}(\mathrm{n}=217)$, $7.0-7.9 \mathrm{~g} / \mathrm{dl}(\mathrm{n}=135)$, and $<7.0 \mathrm{~g} / \mathrm{dl}(\mathrm{n}=105)$, respectively $(P<0.001)$. Multivariate logistic regression showed that initial hemoglobin levels were an independent factor associated with 90-day mortality and mortality proportionally increased with decreasing hemoglobin levels (odds ratio [OR], 1.88; 95\% confidence interval [Cl], 1.36 to 2.61 for $8.0-8.9 \mathrm{~g} / \mathrm{dl} ; \mathrm{OR}$, 1.97; 95\% Cl, 1.31 to 2.95 for $7.0-7.9 \mathrm{~g} / \mathrm{dl}$; and OR, 2.35; 95\% Cl, 1.52 to 3.63 for $<7.0 \mathrm{~g} / \mathrm{dll}$ ).

Conclusions: Low hemoglobin levels $(<9.0 \mathrm{~g} / \mathrm{dl})$ were observed in approximately $20 \%$ of patients with septic shock, and the severity of decrease in these levels correlated with mortality.

Key Words: anemia; mortality; septic shock

\section{INTRODUCTION}

Low hemoglobin levels are frequently observed in patients with septic shock and may have several underlying causes, including reduced red blood cell (RBC) production due to systemic inflammatory response and increased RBC destruction due to hemolysis and bleeding [1]. In these patients, low hemoglobin levels may augment tissue oxygenation impairment by decreasing arterial oxygen concentration. Therefore, maintenance of adequate blood hemoglobin levels has been proposed as a strategy to diminish shock-induced tissue damage [2].

Although immediate hemoglobin correction $<7.0 \mathrm{~g} / \mathrm{dl}$ is one of the goals of transfusion, the critical hemoglobin concentration in critically ill patients at which oxygen delivery get

\section{Original Article}

Received: February 27, 2019

Revised: May 19, 2019

Accepted: May 20, 2019

Corresponding author Won Young Kim Department of Emergency Medicine, Asan Medical Center, University of Ulsan College of Medicine, 88 Olympic-ro 43-gil, Songpa-gu, Seoul 05505, Korea

Tel: +82-2-3010-3350

Fax: +82-2-3010-3360

E-mail:wonpia73@naver.com

Copyright () 2019 The Korean Society of Critical Care Medicine

This is an Open Access article distributed under the terms of Creative Attributions Non-Commercial License (http:// creativecommons.org/li-censes/by-nc/4.0/) which permits unrestricted noncommercial use, distribution, and reproduction in any medium, provided the original work is properly cited. 
impaired, tissue hypoxia ensues, and the risk of adverse outcomes increases has not been determined yet. In patients with septic shock, targeting a hematocrit value of $30 \%$ in those with a low central venous oxygen saturation during the first 6 hours of resuscitation [3] has been proposed [4]. However, blood transfusion has been associated with increased mortality in subgroups of critically ill patients, both in cohort studies and in randomized trial [5-8]. In a recent study investigating optimal hemoglobin levels in cases of septic shock, transfusion thresholds of $7 \mathrm{~g} / \mathrm{dl}$ and $9 \mathrm{~g} / \mathrm{dl}$ were compared and similar 90day mortality rates were observed [9]. Current Surviving Sepsis Campaign guidelines recommend that $\mathrm{RBC}$ transfusion should be performed only when hemoglobin levels decrease to $<7.0 \mathrm{~g} / \mathrm{dl}$ in adults in the absence of extenuating circumstances, such as myocardial ischemia, severe hypoxemia, or acute hemorrhage [10].

Low hemoglobin levels at the time of admission to the emergency department (ED) may indicate insufficient tissue oxygenation and may reflect that inflammation is more severe in such patients than in those with septic shock with normal hemoglobin levels. However, it remains unclear whether the severity of decrease in these levels correlates with patient outcomes. Therefore, we aimed to evaluate the association between initial hemoglobin levels and mortality in patients with septic shock treated with protocol-driven resuscitation bundle therapy at a hospital's ED.

\section{MATERIALS AND METHODS}

\section{Setting and Study Population}

Asan Medical Center has an annual ED patient volume of approximately 110,000 patients and serves as a tertiary referral center in Seoul, Korea. All adult patients (aged $\geq 18$ years) with septic shock in ED and treated with protocol-driven resuscitation bundle therapy were consecutively enrolled, and their data were prospectively collected from the center's septic shock registry. Septic shock was defined as the presence of refractory hypotension (mean arterial pressure $\leq 70 \mathrm{mmHg}$ ) requiring treatment with vasopressors or blood lactate concentration $\geq 4 \mathrm{mmol} / \mathrm{L}$ despite sufficient fluid loading. Patients with a "do not attempt resuscitation" status and those who were transferred to another hospital during the initial resuscitation phase were not included. A single-center, retrospective, observational, and registry-based study was, therefore, conducted to analyze consecutive patients with septic shock diagnosed from June 1, 2012, to December 31, 2016. Study protocol was approved by the Institutional Research Ethics Com-

\section{KEYMESSAGES}

- In patients with septic shock, low hemoglobin levels are frequently observed due to several underlying mechanisms.

- Hemoglobin levels are a critical parameter for oxygen delivery in patients with shock.

- In patients with septic shock, mortality increases with decreasing initial hemoglobin levels.

mittee (No. 2015-1253) and informed consent requirement waived due to the retrospective nature of the study.

\section{Management}

All patients with septic shock were treated with protocol-driven resuscitation bundle therapy, if indicated, including initial crystalloid bolus infusions, blood culture, broad-spectrum antibiotics, vasopressors, lung-protective ventilation, glucocorticoids, and surgical intervention. In accordance with the Surviving Sepsis Campaign guidelines, blood culture was obtained, empirical antibiotic therapy initiated, and initial lactate levels determined within 3 hours of shock recognition. No specific transfusion protocol was followed during the study, with transfusion being performed at the discretion of the treating physician.

\section{Data Collection and Definition}

There are many factors affecting mortality in patients with septic shock, but this study focused on patient's factors. Demographic and clinical data including age, sex, previous medical history, symptoms, initial vital signs, site of infection, and the first laboratory values at the time of admission were retrieved from the septic shock registry [11-15]. Data on initial hemoglobin levels at the time of admission to ED and on whether blood transfusions were performed were also examined to determine the relationship between hemoglobin and mortality. Hemoglobin was applied as a continuous variable, and patients were stratified into four groups according to initial hemoglobin levels: $\geq 9.0 \mathrm{~g} / \mathrm{dl}, 8.0-8.9 \mathrm{~g} / \mathrm{dl}, 7.0-7.9 \mathrm{~g} / \mathrm{dl}$, and $<7.0 \mathrm{~g} / \mathrm{dl}$. Hemoglobin levels $<9.0 \mathrm{~g} / \mathrm{dl}$ were defined as low. In addition, multivariable analysis was performed by adding the Sequential Organ Failure Assessment (SOFA) score to adjust the severity of patients with septic shock. The primary endpoint was 90-day mortality.

\section{Statistical Analysis}

Statistical analyses were performed using IBM SPSS ver. 23.0 
(IBM Corp., Armonk, NY, USA). Continuous variables were expressed as mean \pm standard deviation or median and interquartile range (IQR) if the assumption of a normal distribution was violated. Categorical variables were expressed as numbers and percentages. To adjust for confounding variables and assess possible effect modification, multivariate logistic regression analyses were performed. Results were reported as odds ratio (OR) and $95 \%$ confidence interval (CI). All tests were two-sided, and a P-value $<0.01$ was considered significant.

\section{RESULTS}

A total of 2,265 adult patients with septic shock were enrolled in the ED septic shock registry during the study period. The median age was 70.0 years (IQR, 60 to 78 years), and $58.3 \%$ patients were male. Hypertension was the most common comorbidity, observed in $41.2 \%$ of patients. Initial low hemoglobin levels $(<9.0 \mathrm{~g} / \mathrm{dl})$ were observed in 457 patients $(20.2 \%)$. The characteristics of each group are detailed in Table 1 . For the four groups, 90 -day mortality rates were as follows: $29.1 \%$,

Table 1. Baseline and clinical characteristics of study patients according to initial hemoglobin levels

\begin{tabular}{|c|c|c|c|c|c|c|}
\hline Characteristics & $\begin{array}{c}\text { Total cohort } \\
(n=2,265)\end{array}$ & $\begin{aligned} & \mathrm{Hb} \geq 9.0 \mathrm{~g} / \mathrm{dl} \\
&(\mathrm{n}=1,808)\end{aligned}$ & $\begin{array}{c}\mathrm{Hb} 8.0-8.9 \mathrm{~g} / \mathrm{dl} \\
(\mathrm{n}=217)\end{array}$ & $\begin{array}{c}\mathrm{Hb} 7.0-7.9 \mathrm{~g} / \mathrm{dl} \\
(\mathrm{n}=135)\end{array}$ & $\begin{array}{c}\mathrm{Hb}<7.0 \mathrm{~g} / \mathrm{dl} \\
(\mathrm{n}=105)\end{array}$ & P-value \\
\hline Age (yr) & $70.0(60.0-78.0)$ & $71.0(60.0-78.0)$ & $68.0(59.0-77.0)$ & $69.0(59.0-78.0)$ & $65.0(55.0-72.0)$ & $<0.001$ \\
\hline Male & $1,321(58.3)$ & $1,060(58.6)$ & $116(53.5)$ & $77(57.0)$ & 68 (64.8) & 0.254 \\
\hline \multicolumn{7}{|l|}{ Comorbid disease } \\
\hline Hypertension & $933(41.2)$ & $762(42.1)$ & $89(41.0)$ & $52(38.5)$ & $30(28.6)$ & 0.046 \\
\hline Diabetes mellitus & $690(30.5)$ & $544(30.1)$ & 69 (31.8) & $41(30.4)$ & $36(34.3)$ & 0.795 \\
\hline Cerebrovascular accident & $278(12.3)$ & $234(12.9)$ & $26(12.0)$ & $12(8.9)$ & $6(5.7)$ & 0.094 \\
\hline Chronic pulmonary disease & $180(7.9)$ & $156(8.6)$ & $12(5.5)$ & $9(6.7)$ & $3(2.9)$ & 0.075 \\
\hline Chronic renal disease & $167(7.4)$ & $130(7.2)$ & $17(7.8)$ & $15(11.1)$ & $5(4.8)$ & 0.265 \\
\hline Infection & & & & & & 0.206 \\
\hline Respiratory & $563(24.9)$ & $452(25.0)$ & $59(27.2)$ & $32(23.7)$ & $20(19.0)$ & \\
\hline Urinary & $427(18.9)$ & 359 (19.9) & $36(16.6)$ & $17(12.6)$ & $15(14.3)$ & \\
\hline Gastrointestinal & $293(12.9)$ & $238(13.2)$ & $24(11.1)$ & 21 (15.6) & $10(9.5)$ & \\
\hline Hepatobiliary and pancreas & $408(18.0)$ & $319(17.6)$ & $42(19.4)$ & $24(17.8)$ & 23 (21.9) & \\
\hline Soft tissue & $61(2.7)$ & $52(2.9)$ & $4(1.8)$ & $3(2.2)$ & $2(1.9)$ & \\
\hline Others & $114(5.0)$ & $78(4.3)$ & $16(7.4)$ & $10(7.4)$ & $10(9.5)$ & \\
\hline Mixed & $262(11.6)$ & $205(11.3)$ & $24(11.1)$ & $17(12.6)$ & $16(15.2)$ & \\
\hline Unknown & $137(6.0)$ & $105(5.8)$ & $12(5.5)$ & $11(8.1)$ & $9(8.6)$ & \\
\hline \multicolumn{7}{|l|}{ Laboratory finding } \\
\hline White blood cell count $\left(10^{3} / \mu \mathrm{l}\right)$ & $10.55(5.37-17.15)$ & $11.01(6.00-17.48)$ & $8.80(3.30-14.42)$ & $7.90(2.47-14.86)$ & $6.34(0.64-18.40)$ & $<0.001$ \\
\hline Hemoglobin (g/dl) & $11.1(9.3-12.8)$ & $11.7(10.5-13.1)$ & $8.5(8.2-8.7)$ & $7.6(7.3-7.7)$ & $6.3(5.6-6.6)$ & $<0.001$ \\
\hline Hematocrit (\%) & $33.6(28.6-38.4)$ & $35.4(31.8-39.5)$ & $25.9(25.0-26.8)$ & $22.8(22.0-23.7)$ & $19.0(17.0-20.7)$ & $<0.001$ \\
\hline Platelet $\left(10^{3} / \mu \mathrm{l}\right)$ & 148.0 (83.0-227.8) & $155.5(98.0-234.0)$ & $105.0(49.5-173.0)$ & $89.0(40.0-194.0)$ & $62.0(26.0-199.3)$ & $<0.001$ \\
\hline PT (INR) & $1.26(1.13-1.47)$ & $1.24(1.12-1.43)$ & $1.34(1.17-1.58)$ & $1.37(1.20-1.61)$ & $1.42(1.27-1.61)$ & $<0.001$ \\
\hline Creatinine (mg/dl) & $1.34(0.92-2.14)$ & $1.33(0.92-2.13)$ & $1.38(0.89-2.19)$ & $1.33(0.96-2.26)$ & $1.30(0.99-2.01)$ & 0.904 \\
\hline $\operatorname{CRP}(\mathrm{mg} / \mathrm{dl})$ & $12.4(4.5-21.9)$ & $11.92(3.82-21.64)$ & $13.76(6.32-22.12)$ & $13.25(5.00-22.73)$ & $14.51(7.61-23.45)$ & 0.035 \\
\hline $\mathrm{CRP}>0.6 \mathrm{mg} / \mathrm{dl}$ & 2,102 (92.8) & $1,674(92.6)$ & $205(94.5)$ & $123(91.1)$ & $100(95.2)$ & 0.468 \\
\hline \multicolumn{7}{|l|}{ Severity score } \\
\hline SOFA score & $8.0(6.0-11.0)$ & $8.0(5.0-10.0)$ & $9.0(6.0-11.0)$ & $9.0(6.0-11.0)$ & $9.0(6.0-12.0)$ & $<0.001$ \\
\hline APACHE II score & $19.0(13.0-25.0)$ & $18.0(13.0-24.0)$ & $21.0(16.0-28.0)$ & $20.0(16.0-25.0)$ & $24.0(18.0-30.0)$ & $<0.001$ \\
\hline
\end{tabular}

Values are presented as median (interquartile range) or number (\%).

Hb: hemoglobin; PT: prothrombin time; INR: international normalized ratio; CRP: C-reactive protein; SOFA: Sequential Organ Failure Assessment; APACHE: Acute Physiology and Chronic Health Evaluation. 
$43.0 \%, 46.5 \%$, and $46.9 \%$ for $\geq 9.0 \mathrm{~g} / \mathrm{dl}(\mathrm{n}=1,808), 8.0-8.9 \mathrm{~g} / \mathrm{dl}$ ( $\mathrm{n}=217), 7.0-7.9 \mathrm{~g} / \mathrm{dl}(\mathrm{n}=135)$, and $<7.0 \mathrm{~g} / \mathrm{dl}(\mathrm{n}=105)$, respectively, ( $\mathrm{P}<0.001)$; 90-day mortality increased with decreasing initial hemoglobin levels. Analyses of white blood cell and plate- let counts and prothrombin time revealed that the group with low hemoglobin levels had decreased leukocyte and platelet counts and increased prothrombin time (Table 1).

Patients with septic shock were treated with bundle therapy

Table 2. Treatment and outcomes of study patients according to initial hemoglobin levels

\begin{tabular}{|c|c|c|c|c|c|c|}
\hline Treatment & $\begin{array}{c}\text { Total cohort } \\
(n=2,265)\end{array}$ & $\begin{aligned} H b & \geq 9.0 \mathrm{~g} / \mathrm{dl} \\
(\mathrm{n} & =1,808)\end{aligned}$ & $\begin{array}{c}\mathrm{Hb} 8.0-8.9 \mathrm{~g} / \mathrm{dl} \\
(\mathrm{n}=217)\end{array}$ & $\begin{array}{c}\mathrm{Hb} 7.0-7.9 \mathrm{~g} / \mathrm{dl} \\
(\mathrm{n}=135)\end{array}$ & $\begin{array}{c}\mathrm{Hb}<7.0 \mathrm{~g} / \mathrm{dl} \\
(\mathrm{n}=105)\end{array}$ & P-value \\
\hline Fluid resuscitation $<3 \mathrm{hr}$ & $1,630(72.0)$ & 1,302 (72.1) & 156 (71.9) & $98(72.6)$ & $74(70.5)$ & 0.985 \\
\hline Antibiotic administration $<3 \mathrm{hr}$ & $1,479(65.3)$ & $1,171(64.8)$ & $141(65.0)$ & 95 (70.4) & $72(68.6)$ & 0.525 \\
\hline Vasopressor use & $2,001(88.4)$ & 1,597 (88.4) & 193 (88.9) & $121(89.6)$ & $90(85.7)$ & 0.802 \\
\hline Central line insertion $<6 \mathrm{hr}$ & $1,382(61.0)$ & $1,110(61.4)$ & $125(57.6)$ & $90(66.7)$ & $57(54.3)$ & 0.172 \\
\hline Mechanical ventilator & $628(27.7)$ & $498(27.5)$ & $64(29.5)$ & $29(21.5)$ & 37 (35.2) & 0.114 \\
\hline Renal replacement therapy $<24 \mathrm{hr}$ & 209 (9.2) & $172(9.5)$ & $16(7.4)$ & $8(5.9)$ & $13(12.4)$ & 0.254 \\
\hline \multicolumn{7}{|l|}{ Transfusion $<6 \mathrm{hr}$} \\
\hline $\mathrm{pRBC}$ & $174(7.7)$ & $28(1.5)$ & $31(14.3)$ & 45 (33.3) & $70(66.7)$ & $<0.001$ \\
\hline FFP & $99(4.4)$ & $58(3.2)$ & $11(5.1)$ & $10(7.4)$ & $20(19.0)$ & $<0.001$ \\
\hline PC & $144(6.4)$ & $59(3.3)$ & $31(14.3)$ & $18(13.3)$ & $36(34.3)$ & $<0.001$ \\
\hline \multicolumn{7}{|l|}{ Outcome } \\
\hline 28-Day mortality & $452(21.1)$ & $325(19.1)$ & $56(27.3)$ & $35(26.7)$ & $36(35.0)$ & $<0.001$ \\
\hline 90-Day mortality ${ }^{b}$ & $612(32.5)$ & $433(29.1)$ & $80(43.0)$ & $53(46.5)$ & $46(46.9)$ & $<0.001$ \\
\hline
\end{tabular}

Values are presented as number (\%).

$\mathrm{Hb}$ : hemoglobin; pRBC: packed red blood cell; FFP: fresh frozen plasma; PC: platelet concentrates.

${ }^{a} A$ total of 126 patients (108 in $\mathrm{Hb} \geq 9.0 \mathrm{~g} / \mathrm{dl}, 12$ in $\mathrm{Hb} 8.0-8.9 \mathrm{~g} / \mathrm{dl}, 4$ in Hb 7.0-7.9 g/dl, and 2 in $\mathrm{Hb}<7.0 \mathrm{~g} / \mathrm{dl}$ ) were lost to follow-up; ${ }^{b} \mathrm{~A}$ total of 308 patients (267 in $\mathrm{Hb} \geq 9.0 \mathrm{~g} / \mathrm{dl}, 19$ in $\mathrm{Hb} 8.0-8.9 \mathrm{~g} / \mathrm{dl}, 16$ in $\mathrm{Hb} 7.0-7.9 \mathrm{~g} / \mathrm{dl}$, and 6 in $\mathrm{Hb}<7.0 \mathrm{~g} / \mathrm{dl}$ ) were lost to follow-up.

Table 3. Odds ratios for 90-day mortality rates calculated using univariate and multivariate logistics analyses

\begin{tabular}{|c|c|c|c|c|}
\hline Characteristics & OR $(95 \% \mathrm{Cl})$ & P-value & Adjusted OR (95\% Cl) & P-value \\
\hline Age (yr) & 1.020 (1.012-1.028) & $<0.001$ & $1.027(1.018-1.036)$ & $<0.001$ \\
\hline Female sex & $0.759(0.622-0.926)$ & 0.007 & & \\
\hline \multicolumn{5}{|l|}{ Comorbid disease } \\
\hline Hypertension & 0.969 (0.796-1.179) & 0.752 & & \\
\hline Diabetes mellitus & 1.221 (0.995-1.500) & 0.056 & & \\
\hline Cerebrovascular accident & $1.154(0.859-1.552)$ & 0.342 & & \\
\hline Chronic pulmonary disease & $1.532(1.100-2.134)$ & 0.012 & $1.522(1.072-2.161)$ & 0.019 \\
\hline Chronic renal disease & 1.426 (1.008-2.018) & 0.045 & & \\
\hline \multicolumn{5}{|l|}{ Laboratory finding } \\
\hline Hemoglobin (g/dl) & $0.888(0.853-0.923)$ & $<0.001$ & & \\
\hline \multicolumn{5}{|l|}{ Hemoglobin range (g/dl) } \\
\hline$\geq 9.0$ & Reference & & Reference & \\
\hline $8.0-8.9$ & $1.835(1.345-2.505)$ & $<0.001$ & $1.883(1.358-2.611)$ & $<0.001$ \\
\hline $7.0-7.9$ & $2.113(1.438-3.104)$ & $<0.001$ & 1.966 (1.309-2.953) & 0.001 \\
\hline$<7.0$ & $2.151(1.425-3.249)$ & $<0.001$ & $2.349(1.519-3.630)$ & $<0.001$ \\
\hline Initial SOFA score & 1.199 (1.160-1.239) & $<0.001$ & 1.199 (1.160-1.241) & $<0.001$ \\
\hline $\mathrm{pRBC}$ transfusion $<6 \mathrm{hr}$ & $0.712(0.611-0.830)$ & $<0.001$ & & \\
\hline
\end{tabular}

OR: odds ratio; Cl: confidence interval; SOFA: Sequential Organ Failure Assessment; pRBC: packed red blood cell. 
including fluid therapy, empirical antibiotics, and vasopressors. Intubation, mechanical ventilation, and renal replacement therapy results are summarized in Table 2. No significant differences were observed among the four groups for bundle therapy. Not surprisingly, transfusion frequency was higher in patients with low hemoglobin levels (Table 2).

Multivariate logistic regression analyses revealed that age, chronic pulmonary disease and initial SOFA score were associated with 90-day mortality rate (Table 3). Initial hemoglobin levels were independently associated with 90-day mortality, and mortality proportionally increased with decreasing hemoglobin levels (OR, 1.88; 95\% CI, 1.36 to 2.61 for $8.0-8.9 \mathrm{~g} / \mathrm{dl}$; OR, 1.97; 95\% CI, 1.31 to 2.95 for $7.0-7.9 \mathrm{~g} / \mathrm{dl}$; and OR, 2.35; $95 \% \mathrm{CI}, 1.52$ to 3.63 for $<7.0 \mathrm{~g} / \mathrm{dl}$ ). However, there was no statistical correlation between RBC transfusion within 6 hours and 90-day mortality rate. Further analysis about the association of 28-day mortality and hemoglobin level were summarized in Supplementary Table 1.

\section{DISCUSSION}

Anemia is a common problem in critically ill patients. The present study showed that approximately $20 \%$ of patients with septic shock who visited ED had low hemoglobin levels ( $<9$ $\mathrm{g} / \mathrm{dl}$ ). A large observational study including 3,534 patients from European intensive care units reported mean hemoglobin levels at admission to be $11.3 \mathrm{~g} / \mathrm{dl}$, with $29 \%$ patients having levels $<10 \mathrm{~g} / \mathrm{dl}$ [16]. In a prospective cohort study [17], $55 \%$ of all patients had hemoglobin levels $<9 \mathrm{~g} / \mathrm{dl}$, a higher rate than that observed in the present septic shock cohort. One possible explanation is the fact that blood loss (due to trauma, surgical procedures, or occult gastrointestinal bleeding), one of the most common cause of anemia in critically ill patients, is less common in patients with septic shock. Sepsis is a complex pathophysiological process, and possible underlying mechanisms include microcirculation alterations, decreased RBC production, pre-existing chronic anemia, hemodilution, and increased $\mathrm{RBC}$ destruction due to alterations in RBC membranes.

Current guidelines recommend that the transfusion threshold should be hemoglobin levels $<7 \mathrm{~g} / \mathrm{dl}$, aiming at levels between $7 \mathrm{~g} / \mathrm{dl}$ and $9 \mathrm{~g} / \mathrm{dl}$ in patients without myocardial ischemia, severe hypoxemia, acute hemorrhage, or ischemic coronary artery disease [10]. However, there are limited data supporting these recommendations [10], and many clinicians do not comply with these, despite findings from the transfusion requirements in septic shock trial, which compared transfu- sion thresholds of $7 \mathrm{~g} / \mathrm{dl}$ and $9 \mathrm{~g} / \mathrm{dl}$, showing similar 90-day mortality rates ( $45 \%$ vs. $43 \%$ ) in patients with septic shock [9].

In the present study, we found that percentage of patients with 90-day mortality increased with decreasing initial hemoglobin levels. Moreover, multivariate logistic regression analysis revealed that initial hemoglobin levels were independently associated with 90-day mortality and mortality proportionally increased with decreasing hemoglobin levels. These data suggest that, apart from being a therapeutic target, initial hemoglobin levels may also be a prognostic factor. This hypothesis is consistent with the results from a recent small observational study by Muady et al. [1] reporting that hemoglobin levels on admission independently correlate with survival (OR, 0.83; $95 \%$ CI, 0.75 to 0.92 ). Furthermore, a study of patients with community-acquired pneumonia found that hemoglobin levels $<10 \mathrm{~g} /$ dl were independently associated with 90-day mortality [18]. Although it is known that lower hemoglobin levels in the setting of increased oxygen demand, frequently observed in septic shock cases, may play a negative role and augment organ dysfunction, the prognostic relevance of low hemoglobin levels may alternatively be explained by the fact that it may also reflect older age or a high rate of comorbidities.

Although this study showed that transfusion had no significant association with mortality, previous studies investigating the correlation between blood transfusion and mortality in sepsis found conflicting results [19-21]. As previously mentioned, at the hospital where this study was conducted, decision regarding a blood transfusion relies on the treating physician's discretion rather than on a specific transfusion protocol. Thus, it would be actively administration of blood products in more severely ill patients. The present study revealed poor patient outcomes associated with low hemoglobin levels at presentation. However, due to the observational nature of our study, these results do not support definite conclusions about optimal hemoglobin levels and about an optimal blood transfusion strategy for patients with septic shock. Another limitation of this study that is worth mentioning is its retrospective design, which necessarily impacted data collection, analysis, and interpretation. Although this was addressed through an adjusted multivariate analysis, the potential for bias due to an unmeasured confounder remains. For example, the initial patient's condition may affect mortality, but the physician's management, such as appropriate selection of empirical antibiotics, may also affect patient's mortality. However, data beyond the contents of the registry could not be evaluated. Additionally, this cohort comprised patients from a single medical center; thus, the results may be influenced by re- 
ferral bias. Conversely, the consecutive enrollment of patients with septic shock with a prospective registry reflects a realworld scenario, free of typically observed inclusion biases.

In this study, low hemoglobin levels $(<9.0 \mathrm{~g} / \mathrm{dl})$ were observed in approximately $20 \%$ of patients with septic shock, and the severity of decrease in these levels correlated with mortality. However, transfusion itself was not an independent factor affecting mortality. These findings suggest that initial hemoglobin levels may play a role as a prognostic factor and that a better understanding of the etiology of low hemoglobin levels may prompt the investigation of new preventive therapeutic strategies.

\section{CONFLICT OF INTEREST}

No potential conflict of interest relevant to this article was reported.

\section{ORCID}

Sung Min Jung

https://orcid.org/0000-0002-6992-7088

Youn-Jung Kim https://orcid.org/0000-0003-1385-5836

Seung Mok Ryoo

https://orcid.org/0000-0002-2436-3311

Won Young Kim

https://orcid.org/0000-0002-6904-5966

\section{AUTHOR CONTRIBUTIONS}

Conceptualization: WYK. Data curation: SMJ, YJK. Formal analysis: YJK, SMR. Methodology: SMR, WYK. Project administration: WYK. Visualization: SMJ, YJK. Writing - original draft: SMJ. Writing - review \& editing: WYK.

\section{SUPPLEMENTARY MATERIALS}

The online-only supplement data are available with this article online: https://doi.org/10.4266/acc.2019.00465.

\section{REFERENCES}

1. Muady GF, Bitterman H, Laor A, Vardi M, Urin V, GhanemZoubi N. Hemoglobin levels and blood transfusion in patients with sepsis in Internal Medicine Departments. BMC Infect Dis 2016;16:569.

2. Practice parameters for hemodynamic support of sepsis in adult patients in sepsis. Task Force of the American College of Critical Care Medicine, Society of Critical Care Medicine. Crit Care Med 1999;27:639-60.
3. Rivers E, Nguyen B, Havstad S, Ressler J, Muzzin A, Knoblich $\mathrm{B}$, et al. Early goal-directed therapy in the treatment of severe sepsis and septic shock. N Engl J Med 2001;345:1368-77.

4. ProCESS Investigators, Yealy DM, Kellum JA, Huang DT, Barnato AE, Weissfeld LA, et al. A randomized trial of protocolbased care for early septic shock. N Engl J Med 2014;370:168393.

5. Chatterjee S, Wetterslev J, Sharma A, Lichstein E, Mukherjee D. Association of blood transfusion with increased mortality in myocardial infarction: a meta-analysis and diversity-adjusted study sequential analysis. JAMA Intern Med 2013;173: 132-9.

6. Hébert PC, Wells G, Blajchman MA, Marshall J, Martin C, Pagliarello G, et al. A multicenter, randomized, controlled clinical trial of transfusion requirements in critical care. N Engl J Med 1999;340:409-17.

7. Marik PE, Corwin HL. Efficacy of red blood cell transfusion in the critically ill: a systematic review of the literature. Crit Care Med 2008;36:2667-74

8. Villanueva C, Colomo A, Bosch A, Concepción M, Hernandez-Gea V, Aracil C, et al. Transfusion strategies for acute upper gastrointestinal bleeding. N Engl J Med 2013;368:11-21.

9. Holst LB, Haase N, Wetterslev J, Wernerman J, Guttormsen $A B$, Karlsson S, et al. Lower versus higher hemoglobin threshold for transfusion in septic shock. N Engl J Med 2014;371:138191.

10. Rhodes A, Evans LE, Alhazzani W, Levy MM, Antonelli M, Ferrer R, et al. Surviving sepsis campaign: International Guidelines for Management of Sepsis and Septic Shock: 2016. Intensive Care Med 2017;43:304-77.

11. Kim JS, Kim M, Kim YJ, Ryoo SM, Sohn CH, Ahn S, et al. Troponin testing for assessing sepsis-induced myocardial dysfunction in patients with septic shock. J Clin Med 2019;8:E239.

12. Kim JS, Kim YJ, Ryoo SM, Sohn CH, Seo DW, Ahn S, et al. Oneyear progression and risk factors for the development of chronic kidney disease in septic shock patients with acute kidney injury: a single-centre retrospective cohort study. J Clin Med 2018;7:E554.

13. Ko BS, Cho HY, Ryoo SM, Kim MC, Jung W, Park SH, et al. The prevalence and significance of overt disseminated intravascular coagulation in patients with septic shock in the emergency department according to the third international consensus definition. Korean J Crit Care Med 2016;31:334-41.

14. Ryoo SM, Ahn R, Lee J, Sohn CH, Seo DW, Huh JW, et al. Timing of repeated lactate measurement in patients with septic shock at the emergency department. Am J Med Sci 2018;356: 97-102. 
15. Ryoo SM, Lee J, Lee YS, Lee JH, Lim KS, Huh JW, et al. Lactate level versus lactate clearance for predicting mortality in patients with septic shock defined by sepsis-3. Crit Care Med 2018;46:e489-95.

16. Vincent JL, Baron JF, Reinhart K, Gattinoni L, Thijs L, Webb A, et al. Anemia and blood transfusion in critically ill patients. JAMA 2002;288:1499-507.

17. Chohan SS, McArdle F, McClelland DB, Mackenzie SJ, Walsh TS. Red cell transfusion practice following the transfusion requirements in critical care (TRICC) study: prospective observational cohort study in a large UK intensive care unit. Vox Sang 2003;84:211-8.

18. Reade MC, Weissfeld L, Angus DC, Kellum JA, Milbrandt EB. The prevalence of anemia and its association with 90-day mor- tality in hospitalized community-acquired pneumonia. BMC Pulm Med 2010;10:15.

19. Park DW, Chun BC, Kwon SS, Yoon YK, Choi WS, Sohn JW, et al. Red blood cell transfusions are associated with lower mortality in patients with severe sepsis and septic shock: a propensity-matched analysis. Crit Care Med 2012;40:3140-5.

20. Perner A, Smith SH, Carlsen S, Holst LB. Red blood cell transfusion during septic shock in the ICU. Acta Anaesthesiol Scand 2012;56:718-23.

21. Rosland RG, Hagen MU, Haase N, Holst LB, Plambech M, Madsen KR, et al. Red blood cell transfusion in septic shock: clinical characteristics and outcome of unselected patients in a prospective, multicentre cohort. Scand J Trauma Resusc Emerg Med 2014;22:14. 
Supplementary Table 1. ORs for 28-day mortality rates calculated using univariate and multivariate logistics analyses

\begin{tabular}{|c|c|c|c|c|}
\hline Characteristics & OR $(95 \% \mathrm{Cl})$ & P-value & Adjusted OR (95\% Cl) & P-value \\
\hline Age (yr) & $1.019(1.010-1.027)$ & $<0.001$ & $1.024(1.014-1.033)$ & $<0.001$ \\
\hline Female sex & $0.752(0.607-0.932)$ & 0.009 & & \\
\hline \multicolumn{5}{|l|}{ Comorbid disease } \\
\hline Hypertension & $1.040(0.843-1.284)$ & 0.714 & & \\
\hline Diabetes mellitus & $1.258(1.009-1.568)$ & 0.041 & & \\
\hline Cerebrovascular accident & $1.246(0.918-1.691)$ & 0.157 & & \\
\hline Chronic pulmonary disease & 1.930 (1.373-2.713) & $<0.001$ & 1.999 (1.388-2.880) & $<0.001$ \\
\hline Chronic renal disease & $1.457(1.017-2.088)$ & 0.040 & & \\
\hline \multicolumn{5}{|l|}{ Laboratory finding } \\
\hline Hemoglobin (g/dl) & $0.919(0.882-0.958)$ & $<0.001$ & & \\
\hline \multicolumn{5}{|l|}{ Hemoglobin range (g/dl) } \\
\hline$\geq 9.0$ & Reference & & Reference & \\
\hline $8.0-8.9$ & $0.440(0.288-0.671)$ & $<0.001$ & 1.599 (1.126-2.269) & 0.009 \\
\hline $7.0-7.9$ & $0.699(0.421-1.163)$ & 0.168 & $1.368(0.890-2.103)$ & 0.153 \\
\hline$<7.0$ & $0.679(0.388-1.188)$ & 0.175 & 2.499 (1.590-3.930) & $<0.001$ \\
\hline Initial SOFA score & $1.243(1.201-1.287)$ & $<0.001$ & 1.249 (1.204-1.294) & $<0.001$ \\
\hline $\mathrm{pRBC}$ transfusion $<6 \mathrm{hr}$ & $0.712(0.606-0.836)$ & $<0.001$ & & \\
\hline
\end{tabular}

OR: odds ratio; Cl: confidence interval; SOFA: Sequential Organ Failure Assessment; pRBC: packed red blood cell. 